\title{
ОЦЕНКА ЦИФРОВОЙ ТРАНСФОРМАЦИИ РОССИЙСКОГО ЖЕЛЕЗНОДОРОЖНОГО ТРАНСПОРТА
}

\author{
(c) 2021 Гулый Илья Михайлович \\ кандидат экономических наук, доцент \\ Петербургский государственный университет путей сообщения Императора Александра I, \\ Россия, Санкт-Петербург \\ E-mail: ilya.guliy@mail.ru
}

С учетом сформулированных автором принципов отбора показателей оценки цифровой трансформации компании, предложен их перечень с разделением по блокам: «инвестиционная сфера», «внутренняя операционная эффективность», «внешняя среда взаимодействия с потребителями». На основе перечня показателей проведена оценка цифровой трансформации в крупнейшей транспортной компании России - холдинге «Российские железные дороги». Углублен анализ затрат и результатов цифровой трансформации посредством отраслевого сопоставления холдинга «РЖД» с транспортной отраслью в целом.

Ключевые слова: инвестиции в цифровые технологии, цифрровая трансформация, циффровая бизнесмодель, показатели цифровизации, Российские железные дороги.

\section{Введение}

Повышенное внимание к процессам цифровой трансформации компаний, в частности стратегическому целеполаганию, реализации комплекса инициатив по внедрению цифровых технологий, использованию данных, развитию кадров и культуры цифровых способов организации труда, взаимоотношения с клиентами, механизмам внедрения цифровых решений, предопределило необходимость разработки системы показателей оценки таких процессов. Оценка цифровой трансформации компании должна включать затратную и результативную составляющие [5] с учетом возможности использования статистических показателей, определяемых в формах государственного статистического наблюдения [1], а также применения иных индикаторов, расчет которых возможен с использованием корпоративной статистики и управленческой отчетности.

Цель представленного в статье исследования заключается в обосновании системы показателей оценки цифровой трансформации на примере крупнейшего национального железнодорожного перевозчика - холдинга «Российские железные дороги».

Результаты исследований

Сформулируем основные принципы выбора статистических показателей оценки цифровой трансформации компании:

- соответствие показателей стратегическим целям и задачам компании в области формирования цифровой бизнес-модели (такая позиция также поддерживается авторами в [2, 3]);

- простота и удобство сбора данных при минимальной трудоемкости оценки, возможность использования в процессе планирования и мониторинга готового статистического материала, предоставляемого организациями Росстату в рамках федерального статистического наблюдения, а также имеющейся корпоративной управленческой информационной базы;

- ориентация на соответствие деятельности по внедрению цифровой бизнес-модели, движению в направлении цифровой трансформации, общеэкономическому закону повышения эффективности;

- учет показателей как инвестиционной, так операционной сфер цифровизации.

На наш взгляд, система показателей оценки цифровой трансформации компании должна включать.

Показатели блока «Инвестиционная сфера», а именно:

- объем инвестиций в цифровые технологи и в цифровую трансформацию (далее по тексту инвестиций «в цифру»); 
- доля (удельный вес) инвестиций «в цифру» в доходах - выручке (а также в добавленной стоимости);

- доля (удельный вес) инвестиций «в цифру» в общем объеме инвестиций в компании,\%;

- соотношение (коэффициент опережения) динамики инвестиций «в цифру» и общего объема инвестиций по компании.

Показатели блока «Внутренняя операционная эффективность»:

- оценка снижения операционных затрат за счет цифровой трансформации;

- оценка увеличения операционной прибыли (EBITDA, добавленной стоимости) в результате цифровой трансформации;

- число использованных передовых технологий всего и по видам, а также снижение операционных затрат, прирост операционной прибыли (или EBITDA) на единицу прироста передовых цифровых технологий (также показатель рассмотрен в исследовании [7]).

Показатели блока «Внешняя среда взаимодействия с потребителями».

- доля (удельный вес) цифровых продуктов, услуг - продуктов, услуг, реализованных на базе цифровых платформ, с использованием цифровых сервисов;

- доля (удельный вес) контрагентов (физических, юридических лиц), использующих цифровые решения компании;

- оценка темпа увеличения выручки за счет цифровой трансформации, внедрения цифровых решений.

Приведем данные по предложенной системе показателей на примере холдинга «Российские железные дороги», опираясь на отчетные данные компании за последние 5 лет.

В таблице 1 приведены показатели по холдингу «РЖД» с 2016 по 2020 г.

Абсолютное увеличение ежегодных инвестиций «в цифру» холдинга «Российские железные дороги» за последние 5 лет составило 14\%, значение удельного веса инвестиций в доходах от реализации выросло на $7,4 \%$, в добавленной стоимости на 12,6\% (таблица 1). Доля инвестиций «в цифру» в их общей сумме по железнодорожной компании сократилось с 5 до 3\%. Таким образом, с точки зрения затратной (инвестиционной) составляющей, не произошло существенного увеличения показателей. Несмотря на серьезное внимание к проектам и инициативам цифровизации, реализации в компании стра- тегического документа «Стратегия цифровой трансформации ОАО «РЖД» на период до 2025 года» [4], за последние годы не наблюдалось существенных изменений инвестиционного бюджета.

Результативные показатели оценки цифровой трансформации в «РЖД» имеют более заметную и ощутимую динамику. Доля электронных билетов на поезда дальнего следования выросла с 39\% до 60\%, в 3,2 раза вырос объем онлайн-продаж услуг грузовых перевозок. Доля операционных расходов на оплату труда в себестоимости перевозок сократилась за 5 лет на 3,2 процентных пункта, с 19,7\% до 16,5\%. Рост количества использованных передовых технологий, связанных с цифровыми системами и использованием данных, составил 4\% в 2020 г. (в последний из отчётных периодов показатель несколько сократился, а в\% 2019 г. к 2016 г. рост составлял 26\%). Среднегодовой прирост EBITDA в расчете на единицу прироста передовых цифровых технологий составил 327 млн. рублей. Отметим также положительную тенденцию роста добавленной стоимости в расчете на единицу приведенной работы по инфраструктуре.

Логически последовательным дополнением оценки показателей цифровой трансформации компании, на наш взгляд, является анализ по результатам отраслевых сопоставлений (бенчмаркинг).

Расчет показателей отраслевых сопоставлений показателей цифровой трансформации холдинга «Российские железные дороги» и в целом российского транспорта по данным за 2020 г. приведем в таблице 2.

На рисунке 1 показаны наглядно отраслевые сопоставления удельных инвестиций «в цифру» в холдинге и российском транспорте.

Данные таблицы 2, рисунка 1 позволяют сделать заключение об успехах или недостатках текущего состояния процессов цифровой трансформации в холдинге. Так, сравнительный анализ и сопоставление показателей «РЖД» и транспорта дает основание заключить, что масштабы инвестиций «в цифру», их результативность по показателям прироста EBITDA и снижения доли расходов на оплату труда в полной себестоимости по холдингу значительно выше, чем по отрасли в целом. По рисунку 1 видим, что удельные значения инвестиций в цифровые технологи и в цифровую трансформацию в холдинге на протяжении последних лет опережали 
Таблица 1. Показатели оценки цифровой трансформации холдинга «Российские железные дороги»

\begin{tabular}{|c|c|c|c|c|c|c|c|}
\hline \multirow[b]{2}{*}{ Показатели } & \multirow[b]{2}{*}{2016 г. } & \multirow[b]{2}{*}{2017 г. } & \multirow[b]{2}{*}{2018 г. } & \multirow[b]{2}{*}{2019 г. } & \multirow[b]{2}{*}{2020 г. } & \multicolumn{2}{|c|}{$\begin{array}{l}\text { Изменение в } \\
2020 \text { г. к } 2016 \text { г. }\end{array}$} \\
\hline & & & & & & \begin{tabular}{|c|} 
абсо- \\
лютное, \\
соотв. \\
ед. из- \\
мерения
\end{tabular} & $\begin{array}{l}\text { прирост } \\
\text { / сниже- } \\
\text { ние, \% }\end{array}$ \\
\hline \multicolumn{8}{|c|}{ Инвестиционная сфера } \\
\hline $\begin{array}{l}\text { Объем инвестиций в цифровые } \\
\text { технологи и в цифровую трансфор- } \\
\text { мацию, млн. рублей }\end{array}$ & 18,8 & 17,0 & 16,4 & 18,1 & 21,3 & 2,5 & 13,6 \\
\hline $\begin{array}{l}\text { Доля (удельный вес) инвестиций } \\
\text { «в цифру» в выручке, \% }\end{array}$ & 0,87 & 0,84 & 0,76 & 0,79 & 0,94 & 0,06 & 7,4 \\
\hline $\begin{array}{l}\text { Доля (удельный вес) инвестиций } \\
\text { «в цифру» добавленной стоимости, } \\
\%\end{array}$ & 1,48 & 1,18 & 1,00 & 0,99 & 1,66 & 0,19 & 12,6 \\
\hline $\begin{array}{l}\text { Доля (удельный вес) инвестиций } \\
\text { «в цифру» в общем объеме инвести- } \\
\text { ций в компании, \% }\end{array}$ & 5,0 & 3,5 & 3,1 & 2,7 & 3,0 & $-2,0$ & $-40,5$ \\
\hline \multicolumn{8}{|c|}{ Внутренняя операционная эффективность } \\
\hline $\begin{array}{l}\text { Оценка снижения доли расходов на } \\
\text { оплату труда в полной себестоимо- } \\
\text { сти за счет цифровой трансформа- } \\
\text { ции, процентных пунктов к преды- } \\
\text { дущему году }\end{array}$ & $-0,04$ & $-1,47$ & 0,05 & $-2,17$ & 0,64 & $-2,98$ & $\mathrm{x}$ \\
\hline $\begin{array}{l}\text { Добавленная стоимость в расчете на } \\
10 \text { тонно-км приведенной работы } \\
\text { по инфраструктуре, рублей / через } \\
\text { дробь - темп роста к предыдущему } \\
\text { году в \% }\end{array}$ & $\stackrel{4,7}{101,2}$ & $\frac{4,9}{104,6}$ & $\frac{5,1}{104,5}$ & $\underline{5,6}$ & $\frac{3,9}{69,7}$ & $-0,8$ & $-17,7$ \\
\hline $\begin{array}{l}\text { Число использованных передовых } \\
\text { технологий всего, единиц }\end{array}$ & 2033 & 2128 & 2186 & 2568 & 2113 & 80 & 3,9 \\
\hline $\begin{array}{l}\text { Прирост/снижение EBITDA на еди- } \\
\text { ницу прироста передовых цифро- } \\
\text { вых технологий, млн. рублей }\end{array}$ & $-46,1$ & 402,1 & 453,4 & 514,9 & 343,3 & $-58,8^{*}$ & $-14,6^{*}$ \\
\hline \multicolumn{8}{|c|}{ Внешняя среда взаимодействия с потребителями } \\
\hline $\begin{array}{l}\text { Доля электронных билетов на поез- } \\
\text { да дальнего следования, \% }\end{array}$ & 38,5 & 46,0 & 51,0 & 57,4 & 60,0 & 21,5 & 55,8 \\
\hline $\begin{array}{l}\text { Объем онлайн-продаж услуг грузо- } \\
\text { вых перевозок, млрд. рублей }\end{array}$ & $\begin{array}{l}\text { нет дан- } \\
\text { ных }\end{array}$ & 7,4 & 14,0 & 19,0 & 23,8 & $16,4^{*}$ & в 3,2 p.* \\
\hline
\end{tabular}

* Примечание: 2020 г. к 2017 г.

Источник: расчеты автора на основе [1, 6].

Таблица 2. Показатели цифровой трансформации холдинга «РЖД» и транспорта РФ в 2020 году

\begin{tabular}{|l|c|c|}
\hline \multicolumn{1}{|c|}{ Показатели } & $\begin{array}{c}\text { Холдинг } \\
\text { «ЖЖД» }\end{array}$ & $\begin{array}{c}\text { Транспорт } \\
\text { РФ * }\end{array}$ \\
\hline Доля (удельный вес) инвестиций «в цифру» в выручке, \% & 0,9 & 0,6 \\
\hline Доля (удельный вес) инвестиций «в цифру» в добавленной стоимости, \% & 1,7 & 1,0 \\
\hline Доля (удельный вес) инвестиций «в цифру» в общем объеме инвестиций, \% & 3,0 & 3,9 \\
\hline $\begin{array}{l}\text { Оценка снижения расходов на оплату труда в себестоимости перевозок за счет } \\
\text { цифровой трансформации с 2016 по 2020 г., процентных пункта }\end{array}$ & $-3,2$ & $-1,4$ \\
\hline $\begin{array}{l}\text { Прирост/снижение ЕВITDА на единицу прироста передовых цифровых техно- } \\
\text { логий, млн. рублей }\end{array}$ & 343,3 & 144,2 \\
\hline
\end{tabular}

* Вид деятельности «транспортирование и хранение».

Источник: расчеты автора на основе [1]. 


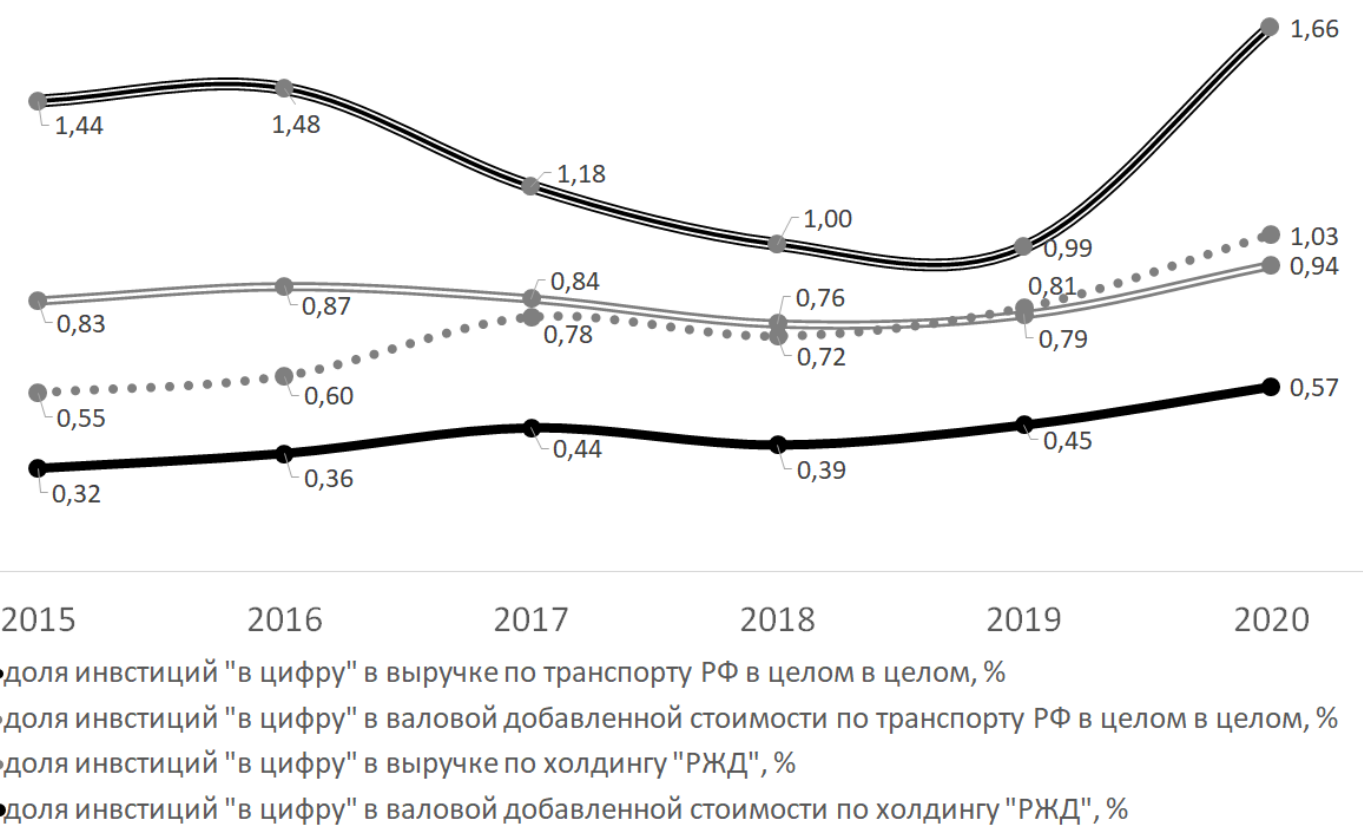

Puc. 1. Динамика показателей доли инвестиций «в цифру» в выручке и добавленной стоимости в целом по российскому транспорту и отдельно холдингу «РЖД» с 2015 по 2020 гг. Источник: рассчитано и построено автором на основе [1].

средние отраслевые значения в 2,5 раза в 20152016 гг., в 1,7 раза в 2017-2020 гг.

Заключение

Таким образом, использование системы показателей оценки цифровой трансформации в холдинге «Российские железные дороги» позволяет заключить, что несмотря на отсутствие за последние годы ярко выраженной динамики инвестиций «в цифру», компании удалось достичь заметных результатов: сокращения доли затрат труда в полной себестоимости транспортных услуг, ежегодного прироста количества используемых цифровых технологий, добавленной стоимости, операционной прибыли. Наиболее высокая динамика результативных показателей выявлена по цифровому взаимодействию компании с потребителями: ежегодный прирост электронных продаж по пассажирскому комплексу (перевозки в дальнем следовании) составил более $7 \%$, по грузоперевозкам - более $30 \%$.

\section{Библиографический список}

1. ЕМИСС. Государственная статистика: официальные статистические показатели [Электронный ресурс]. URL: https:/fedstat.ru (дата обращения: 20.10.21).

2. Журавлева Н.А. Проблемы внедрения цифровых технологий на транспорте // Транспорт Российской Федерации. 2019. № 3 (82). С. 19-22.

3. Методические рекомендации по цифровой трансформации государственных корпораций и компаний с государственным участием [Электронный ресурc]. URL: https://digital.gov.ru (дата обращения: 20.10.21).

4. Стратегия цифровой трансформации ОАО «РЖД» до 2025 г.: утв. Советом директоров ОАО «РЖД» 25.10.2019 [Электронный ресурс]. URL: https://consultant.ru. (дата обращения: 20.10.21).

5. Федеральный проект «Цифровые технологии»: утв. протоколом заседания президиума Правительственной комиссии по цифровому развитию, использованию информационных технологий для улучшения качества жизни и условий ведения предпринимательской деятельности от 28 мая 2019 г. № 9 [Электронный ресурс]. URL: https://consultant.ru. (дата обращения: 20.10.21).

6. Чаркин Е.И. Цифровая трансформация холдинга «РЖД» // Железнодорожный транспорт. 2019. № 2. С. 5963.

7. Чеченова Л.М. Интеллектуализация железнодорожного транспорта как фактор развития транспортной отрасли // Вестник транспорта Поволжья. 2021. № 2 (86). С. 78-85. 